Article

\title{
Invasive Fungal Rhinosinusitis with and without Orbital Complications: Clinical and Laboratory Differences
}

\author{
Kuan-Hsiang Twu ${ }^{1,2}$, Ying-Ju Kuo ${ }^{2,3}{ }^{\circ}$, Ching-Yin Ho ${ }^{2,4}$, Edward C. Kuan ${ }^{5}$, Wei-Hsin Wang ${ }^{2,6}$ and \\ Ming-Ying Lan 1,2,*(D) \\ 1 Department of Otolaryngology-Head and Neck Surgery, Taipei Veterans General Hospital, \\ Taipei 11217, Taiwan; wingstwu@gmail.com \\ 2 School of Medicine, National Yang Ming Chiao Tung University, Taipei 11221, Taiwan; \\ yjkuo2@vghtpe.gov.tw (Y.-J.K.); tigertpe@gmail.com (C.-Y.H.); weihsin0103@gmail.com (W.-H.W.) \\ 3 Department of Pathology, Taipei Veterans General Hospital, Taipei 11217, Taiwan \\ 4 Department of Otolaryngology, Cheng Hsin General Hospital, Taipei 11220, Taiwan \\ 5 Department of Otolaryngology-Head and Neck Surgery, University of California, Irvine, CA 92868, USA; \\ eckuan@hs.uci.edu \\ 6 Department of Neurosurgery, Taipei Veterans General Hospital, Taipei 11217, Taiwan \\ * Correspondence: mingyinglan@gmail.com; Tel.: +886-2-2875-7337
}

Citation: Twu, K.-H.; Kuo, Y.-J.; Ho, C.-Y.; Kuan, E.C.; Wang, W.-H.; Lan, M.-Y. Invasive Fungal Rhinosinusitis with and without Orbital Complications: Clinical and Laboratory Differences. J. Fungi 2021, 7,573. https://doi.org/10.3390/ jof7070573

Academic Editor: Livio Pagano

Received: 20 June 2021

Accepted: 16 July 2021

Published: 18 July 2021

Publisher's Note: MDPI stays neutral with regard to jurisdictional claims in published maps and institutional affiliations.

Copyright: (c) 2021 by the authors. Licensee MDPI, Basel, Switzerland. This article is an open access article distributed under the terms and conditions of the Creative Commons Attribution (CC BY) license (https:/ / creativecommons.org/licenses/by/ $4.0 /)$.

\begin{abstract}
Background: Invasive fungal rhinosinusitis (IFS) is a rare but often fatal disease. There are limited studies regarding IFS with orbital complications (IFSwOC). The present study aimed to identify the clinical signs associated with IFSwOC and prognosticators of the disease. Methods: A retrospective case series was conducted of patients histopathologically confirmed IFS or fungal rhinosinusitis with clinically apparent neuro-orbital complications who underwent surgery between 2008 and 2018. Demographic data, presenting symptoms and signs, culture data, laboratory results, and patient outcomes were obtained from medical records. Results: A total of 38 patients were identified, including 9 patients with IFSwOC, and 29 patients with IFS without orbital complications (IFSsOC). The clinical signs associated with developing orbital complications include headache, fever, sphenoid sinus, or posterior ethmoid sinus involvement, CRP level $\geq 1.025 \mathrm{mg} / \mathrm{dL}$, or ESR level $\geq 46.5 \mathrm{~mm} / \mathrm{h}$. In IFSwOC group, male, posterior ethmoid sinus involvement, WBC count $\geq 9000 \mu \mathrm{L}, \mathrm{CRP}$ level $\geq 6.91 \mathrm{mg} / \mathrm{dL}$, or ESR level $\geq 69 \mathrm{~mm} / \mathrm{h}$ were correlated with a significantly poorer prognosis. Conclusion: IFS patients with sphenoid or posterior ethmoid sinus involvement, headache or fever as presenting symptoms, elevated CRP, and ESR level were at risk of developing orbital complications. Timely surgical debridement followed by systemic antifungal treatment may improve treatment outcomes.
\end{abstract}

Keywords: invasive fungal rhinosinusitis; orbital complications; fungal rhinosinusitis; Aspergillus; Mucor

\section{Introduction}

The diagnosis of invasive fungal rhinosinusitis (IFS) is made by histopathologic confirmation of fungal hyphae invading mucosal or submucosal tissues, vasculature, or bones [1]. According to differences in histopathology, IFS may be classified into three categories: acute invasive fungal rhinosinusitis (AIFS), chronic invasive fungal rhinosinusitis (CIFS), and granulomatous invasive fungal rhinosinusitis (GIFS) [1]. Although rare, IFS is a challenging condition for otolaryngologists owing to its tendency to cause serious injury to surrounding vital structures and association with high mortality rates if left untreated. According to a large systemic review of 807 patients of AIFS, $49.6 \%$ developed orbital invasion, $21.2 \%$ had intracranial extension, and $8.6 \%$ had cavernous sinus involvement [2]. Based on previous studies, reported mortality rate of AIFS is usually over $50 \%$ and can be as high as $80 \%$ [2-5].

Among the various complications of IFS, almost half of patients develop orbital complications [2], including orbital cellulitis, orbital abscess, decreased vision, proptosis, 
and diplopia. It is known that intracranial extension negatively impacts survival of patients with IFS [2,6-9]. Limited reports have found that orbital involvement was not a negative prognostic factor in IFS [2], and orbital exenteration did not appear to improve survival [2,10].

Many fungal species have been found to cause IFS, but the most commonly identified organisms are Aspergillus and Mucor (Zygomycetes) [2,3,5,11]. After fungus breaks through sinonasal mucosa, it can spread to the orbital apex, cavernous sinus, and finally intracranial structures. Once angioinvasion occurs, thrombosis and mycotic aneurysms could develop, resulting in ischemia, infarction, intracranial hemorrhage, and other neurologic symptoms [12-16]. Whether different fungal species had an impact on survival is still controversial. There is evidence suggesting that IFS due to mucormycosis was associated with a higher mortality rate than those related to Aspergillus infections $[5,17]$. On the other hand, a systematic review conducted by Turner et al. showed no statistically significant impact on overall survival among different types of fungal species [2].

Because of the rarity of IFS, there are few studies focusing on orbital complications in IFS, and are generally limited to case series. The objective of the current study is to identify the clinical signs associated with IFSwOC and also to seek possible factors that could negatively impact treatment outcomes of IFS with orbital involvement.

\section{Materials and Methods}

\subsection{Patients}

All procedures performed in studies involving human participants were in accordance with the ethical standards of the Institutional Review Board (IRB) of Taipei Veterans General Hospital (IRB NO: 2018-12-004CC), and with the 1964 Helsinki declaration and its later amendments or comparable ethical standards. We retrospectively reviewed the medical records of patients who had histopathologically confirmed IFS or fungal rhinosinusitis with clinically apparent neuro-orbital complications who underwent surgery between November 2008 and May 2018 at a tertiary academic medical center. Neuro-orbital complications included diplopia, blurred vision, proptosis, ptosis, or other central neurological signs/symptoms, such as hemiparesis, seizure, or altered mental status. Patients less than 18 years of age, or those who did not receive surgical treatment, were excluded.

Demographic data, underlying medical problems, presenting symptoms and signs, fungal and bacterial culture results, laboratory results, imaging studies, use of antifungal agents, and survival outcomes were obtained. The patients were divided into two groups based on whether they had orbital complications: IFS with orbital complications (IFSwOC) and IFS without orbital complications (IFSsOC). In the orbital complication group, the endpoint was defined as either mortality or long-term unrecovered sequelae.

\subsection{Statistical Analysis}

Chi-square tests or Fisher's exact tests were used for comparisons of categorical variables. Independent Student's t-tests or Mann-Whitney U tests were used for comparisons of continuous variables based on the distribution of the data. Receiver operating characteristic (ROC) curves and area under the curve (AUC) were used to analyze continuous variables, and cut-off values were calculated corresponding to the maximal value of Youden's index. All statistical analyses were conducted using SPSS Statistics for Windows, Version 25.0 (Armonk, NY, USA: IBM Corp.). A p-value < 0.05 was considered statistically significant.

\section{Results}

\subsection{Demographic Data, Lab Data, and Symptoms}

Thirty-eight patients were included in this study. The mean age was 61.2 years (range 39-87 years); 24 were female and 14 were male. 9 (23.7\%) patients presented with orbital complications. Six patients (15.8\%) had AIFS and 32 patients $(84.2 \%)$ had CIFS. Table 1 demonstrates baseline patient demographic data. There was no significant difference between the two groups regarding age, gender, laterality of involvement, and 
underlying comorbidities $(p>0.05)$. None of the patients in either group was neutropenic at the time of diagnosis; in addition, IFSwOC group had a higher absolute neutrophil count $\left(10,229.56\right.$ cells $\left./ \mathrm{mm}^{3}\right)$ than IFSsOC group $\left(4194.62\right.$ cells $\left./ \mathrm{mm}^{3}\right)$, although it was not statistically significant $(p>0.05)$. When comparing the involved sinuses between the two groups, it was found that sphenoid and posterior ethmoid sinus involvement was significantly more prevalent in the IFSwOC group ( $p=0.035$ and 0.001 , respectively), whereas maxillary sinus involvement was more common in IFSsOC $(p=0.002)$ (Figure 1). Anterior ethmoid sinus involvement showed no significant difference between the two groups, and there were no cases presented with frontal sinus disease in our cohort. In the IFSwOC group, the common initial presentations included headache $(n=7,77.8 \%)$, diplopia $(n=6,66.7 \%)$, and fever $(n=5,55.6 \%)$ (Table 1$)$. In the IFSsOC group, the most common presenting symptom was purulent rhinorrhea $(n=14,48.3 \%)$, followed by nasal obstruction $(n=8,27.6 \%)$. In addition to orbital symptoms, IFSwOC group had statistically significantly higher rates of headache and fever $(p=0.002$ and $<0.001$, respectively) than IFSsOC group. All of the patients got either a computed tomography (CT), magnetic resonance imaging (MRI), or both, at the time of diagnosis. Seven patients in IFSwOC group could identify cavernous sinus and/or orbital involvements on the scans, and no patients in IFSsOC group had positive findings for cavernous sinus or orbital invasion.

Table 1. Comparison of demographic data, lab data, symptoms and imaging results between IFSsOC and IFSwOC.

\begin{tabular}{|c|c|c|c|c|}
\hline & $\begin{array}{l}\text { All Patients } \\
\quad(n=38) \\
\text { No. }(\%)\end{array}$ & $\begin{array}{c}\text { IFSsOC } \\
(n=29) \\
\text { No. }(\%)\end{array}$ & $\begin{array}{c}\text { IFSwOC } \\
(n=9) \\
\text { No. }(\%)\end{array}$ & $p$ Value \\
\hline Age (mean \pm SD) & $61.18 \pm 12.30$ & $60.03 \pm 12.10$ & $64.89 \pm 12.96$ & 0.308 \\
\hline Gender (male: female) & $14: 24$ & $11: 18$ & $3: 6$ & 1.000 \\
\hline Classification & & & & $<0.001$ \\
\hline Acute invasive & $6(15.8)$ & $0(0.0)$ & $6(66.7)$ & \\
\hline Chronic invasive & $32(84.2)$ & $29(100.0)$ & $3(33.3)$ & \\
\hline \multicolumn{5}{|l|}{ Side } \\
\hline Left & $22(57.9)$ & $17(58.6)$ & $5(55.6)$ & 1.000 \\
\hline Right & $18(47.4)$ & $12(41.4)$ & $6(66.7)$ & 0.260 \\
\hline \multicolumn{5}{|l|}{ Location } \\
\hline Maxillary & $26(68.4)$ & $24(82.8)$ & $2(22.2)$ & 0.002 \\
\hline Sphenoid & $11(28.9)$ & $4(13.8)$ & $7(77.8)$ & 0.001 \\
\hline Anterior ethmoid & $3(7.9)$ & $2(6.9)$ & $1(11.1)$ & 1.000 \\
\hline Posterior ethmoid & $4(10.5)$ & $1(3.4)$ & $3(33.3)$ & 0.035 \\
\hline Others * & $2(5.3)$ & $2(6.9)$ & $0(0.0)$ & 1.000 \\
\hline \multicolumn{5}{|l|}{ Underlying Diseases } \\
\hline Hypertension & $11(28.9)$ & $6(20.7)$ & $5(55.6)$ & 0.088 \\
\hline Diabetes mellitus & $7(18.4)$ & $4(13.8)$ & $3(33.3)$ & 0.322 \\
\hline Coronary artery disease & $5(13.2)$ & $3(10.3)$ & $2(22.2)$ & 0.574 \\
\hline Chronic kidney disease & $1(2.6)$ & $1(3.4)$ & $0(0.0)$ & 1.000 \\
\hline Hyperlipidemia & $5(13.2)$ & $4(13.8)$ & $1(11.1)$ & 1.000 \\
\hline Atrial fibrillation & $2(5.3)$ & $1(3.4)$ & $1(11.1)$ & 0.422 \\
\hline Autoimmune disease & $2(5.3)$ & $2(6.9)$ & $0(0.0)$ & 1.000 \\
\hline \multicolumn{5}{|l|}{ Lab Data } \\
\hline WBC $(/ \mu \mathrm{L})$ & $8252.63 \pm 5850.74$ & $6686.21 \pm 1796.97$ & $13,300.00 \pm 10,462.43$ & 0.066 \\
\hline $\mathrm{ANC}(/ \mu \mathrm{L})$ & $5623.95 \pm 5660.50$ & $4194.62 \pm 1619.37$ & $10,229.56 \pm 10,379.96$ & 0.103 \\
\hline CRP (mg/dL) & $4.50 \pm 8.17$ & $0.53 \pm 0.92$ & $9.79 \pm 10.52$ & $<0.001$ \\
\hline $\operatorname{ESR}(\mathrm{mm} / \mathrm{h})$ & $42.35 \pm 32.37$ & $28.67 \pm 23.34$ & $62.88 \pm 34.44$ & 0.031 \\
\hline $\begin{array}{l}\text { Symptoms Duration } \\
\text { (days, mean } \pm \text { SD) }\end{array}$ & $236.22 \pm 631.58$ & $297.52 \pm 736.53$ & $79.56 \pm 124.36$ & 0.389 \\
\hline Purulent rhinorrhea & $14(36.8)$ & $14(48.3)$ & $0(0.0)$ & 0.014 \\
\hline Headache & $12(31.6)$ & $5(17.2)$ & $7(77.8)$ & 0.002 \\
\hline Nasal obstruction & $8(21.1)$ & $8(27.6)$ & $0(0.0)$ & 0.159 \\
\hline Diplopia & $6(15.8)$ & $0(0.0)$ & $6(66.7)$ & $<0.001$ \\
\hline Fever & $5(13.2)$ & $0(0.0)$ & $5(55.6)$ & $<0.001$ \\
\hline Foul odor & $5(13.2)$ & $5(17.2)$ & $0(0.0)$ & 0.312 \\
\hline Blood-tinged rhinorrhea & $4(10.5)$ & $4(13.8)$ & $0(0.0)$ & 0.554 \\
\hline Facial pain/fullness & $4(10.5)$ & $4(13.8)$ & $0(0.0)$ & 0.554 \\
\hline Blurred vision & $3(7.9)$ & $0(0.0)$ & $3(33.3)$ & 0.010 \\
\hline
\end{tabular}


Table 1. Cont.

\begin{tabular}{|c|c|c|c|c|}
\hline & $\begin{array}{l}\text { All Patients } \\
(n=38) \\
\text { No. }(\%)\end{array}$ & $\begin{array}{c}\text { IFSsOC } \\
(n=29) \\
\text { No. }(\%)\end{array}$ & $\begin{array}{c}\text { IFSwOC } \\
(n=9) \\
\text { No. }(\%)\end{array}$ & $p$ Value \\
\hline Proptosis & $2(5.3)$ & $0(0.0)$ & $2(22.2)$ & 0.051 \\
\hline Ptosis & $2(5.3)$ & $0(0.0)$ & $2(22.2)$ & 0.051 \\
\hline Facial numbness & $2(5.3)$ & $2(6.9)$ & $0(0.0)$ & 1.000 \\
\hline Facial swelling & $2(5.3)$ & $1(3.4)$ & $1(11.1)$ & 0.422 \\
\hline $\begin{array}{l}\text { Consciousness } \\
\text { disturbance }\end{array}$ & $1(2.6)$ & $0(0.0)$ & $1(11.1)$ & 0.237 \\
\hline $\begin{array}{l}\text { Imaging Results } \\
\text { Cavernous sinus or } \\
\text { orbital involvement } \\
\text { suspected on CT/MRI }\end{array}$ & $7(18.4)$ & $0(0.0)$ & $7(77.8)$ & $<0.001$ \\
\hline
\end{tabular}

Abbreviations: IFS, invasive fungal rhinosinusitis; SD, standard deviation; WBC, white blood cell; ANC, absolute neutrophil count; CRP, C-reactive protein; ESR, erythrocyte sedimentation rate; CT, computed tomography; MRI, magnetic resonance imaging. * other locations: 1 in nasal septum, 1 in bilateral maxillary sinuses, nasopharynx, clivus, and parapharyngeal space. Bold indicates statistically significant $(p<0.05)$.

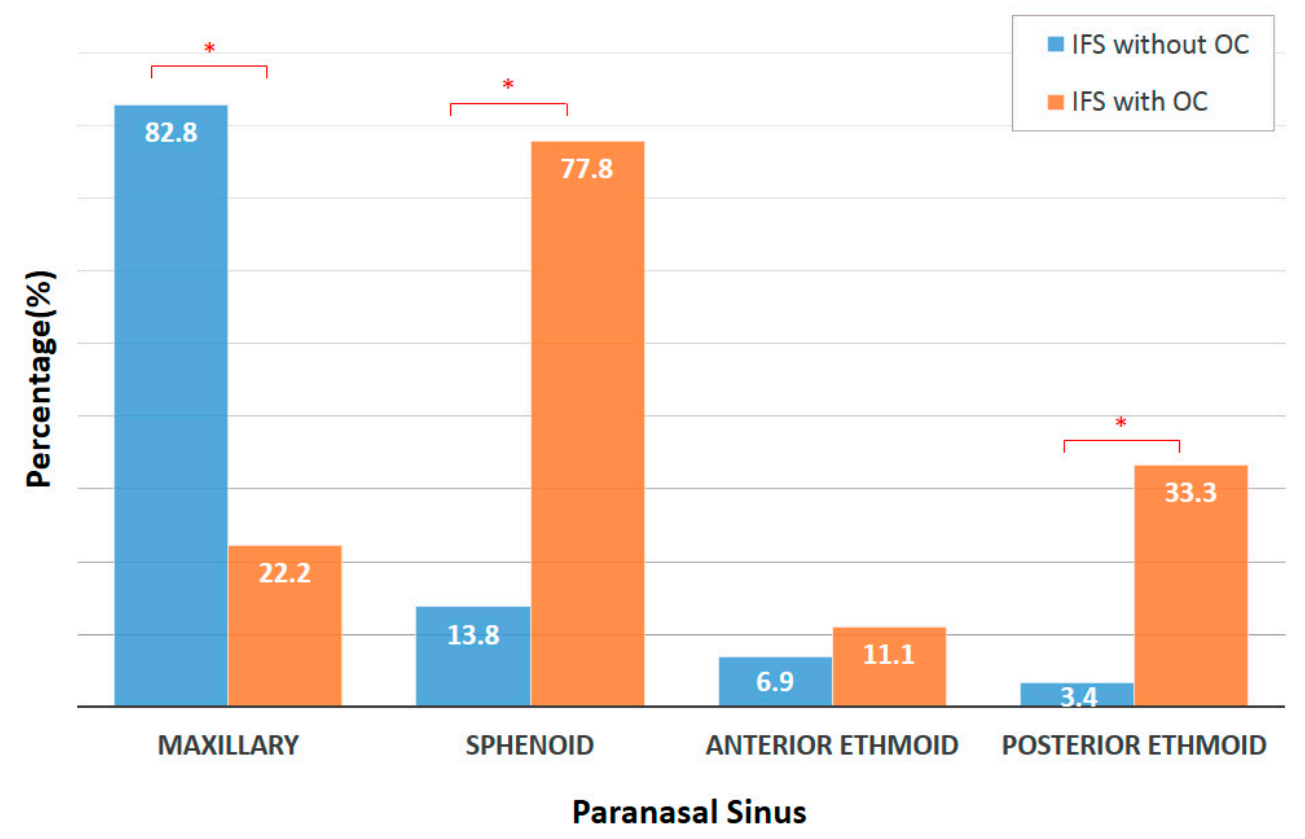

Figure 1. Sinus involvement in IFS. (* statistically significant $(p<0.05))$.

\subsection{Microbiology}

Overall, Aspergillus was the predominant identified fungal species (77.1\%), followed by Mucor (8.6\%) and Scedosporium (2.9\%) (Supplementary Table S1) (Figure 2). Fungal rhinosinusitis is usually accompanied with bacteria co-infection. Among the various isolated bacteria species, Hemophilus influenza, Staphylococcus aureus, and Propionibacterium spp. were most commonly seen (16.1\% each). There was no statistically significant difference in the prevalence of causative fungal or bacterial pathogens between the two groups. The mean white blood cell (WBC) count was higher in the IFSwOC group $\left(13,300\right.$ cells $\left./ \mathrm{mm}^{3}\right)$ than in the IFSsOC group $\left(6686\right.$ cells $\left./ \mathrm{mm}^{3}\right)$, though this did not reach statistical significance $(p=0.066)$. In the IFSwOC group, the mean C-reactive protein (CRP) and erythrocyte sedimentation rate (ESR) level was $9.79 \mathrm{mg} / \mathrm{dL}$ and $62.88 \mathrm{~mm} / \mathrm{h}$, respectively, whereas the mean CRP and ESR level in IFSsOC group was $0.53 \mathrm{mg} / \mathrm{dL}$ and $28.67 \mathrm{~mm} / \mathrm{h}$, respectively. Both CRP and ESR level were significantly higher in IFSwOC group than IFSsOC group ( $p<0.001$ and $p=0.031$, respectively). 


\section{A}

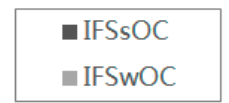

Fungus

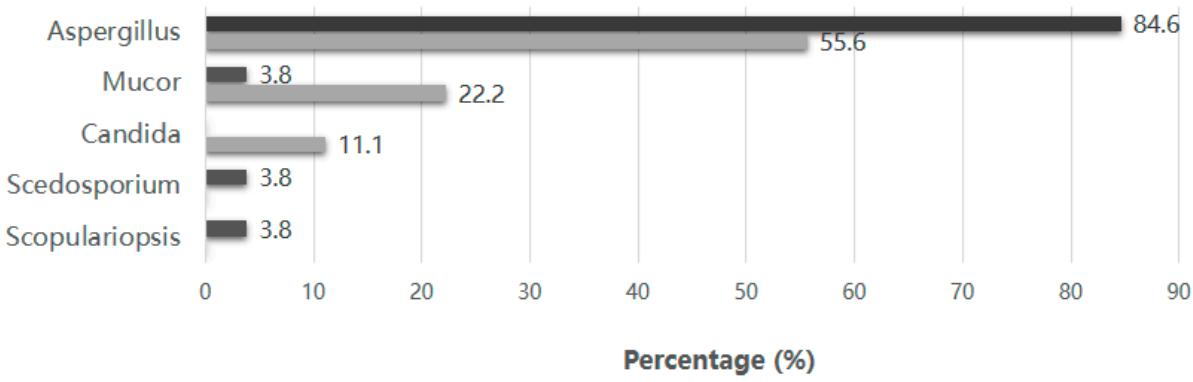

B

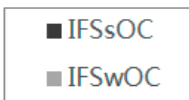

Bacteria

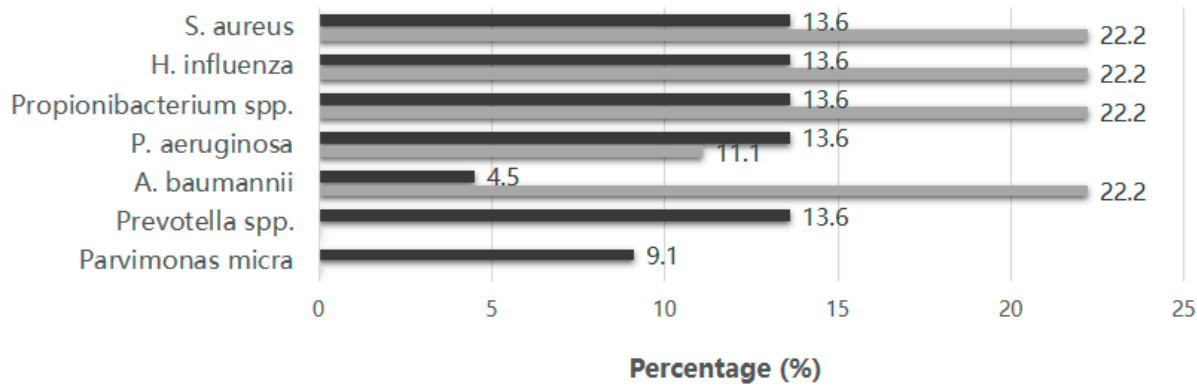

Figure 2. Microbiology in IFS (A) fungus and (B) bacteria.

\subsection{Treatment and Outcome}

We investigated treatment modalities and associated outcomes (Table 2). In addition to surgical treatment, all $(100 \%)$ patients with orbital complications received systemic antifungal therapy, while only $65.5 \%$ of IFSsOC patients had systemic antifungal treatment. In accordance with microbiology, the most commonly used antifungal agent was voriconazole. Mean follow-up duration was 275 days (range 13 to 1303 days). Overall, three out of nine patients in IFSwOC group had poor prognoses (Supplementary Table S2). On the other hand, all patients in IFSsOC group improved clinically without any complications. Mortality rate was $2.6 \%$ in all patients, $11.1 \%$ in IFSwOC group, and $16.7 \%$ in AIFS patients.

Table 2. Treatment and Outcome.

\begin{tabular}{|c|c|c|c|c|}
\hline & $\begin{array}{l}\text { All Patients } \\
\quad(n=38) \\
\text { No. }(\%)\end{array}$ & $\begin{array}{c}\text { IFSsOC } \\
(n=29) \\
\text { No. }(\%)\end{array}$ & $\begin{array}{c}\text { IFSwOC } \\
(n=9) \\
\text { No. }(\%)\end{array}$ & $p$ Value \\
\hline $\begin{array}{l}\text { Follow-up Duration } \\
\text { (days) }\end{array}$ & $275.43 \pm 262.01$ & $286.76 \pm 284.83$ & $220.67 \pm 90.26$ & 0.983 \\
\hline $\begin{array}{l}\text { Surgery } \\
\text { Interval between }\end{array}$ & & & & \\
\hline $\begin{array}{l}\text { onset of symptoms } \\
\text { and surgery (days) }\end{array}$ & $107.13 \pm 99.19$ & $145.14 \pm 93.77$ & $14.22 \pm 11.38$ & $<0.001$ \\
\hline \multicolumn{5}{|l|}{ Antifungal Therapy } \\
\hline Voriconazole & $24(63.2)$ & $17(58.6)$ & $7(77.8)$ & 0.438 \\
\hline Amphotericin B & $1(2.6)$ & $0(0.0)$ & $1(11.1)$ & 0.237 \\
\hline $\begin{array}{l}\text { Liposomal } \\
\text { amphotericin B }\end{array}$ & $2(5.3)$ & $0(0.0)$ & $2(22.2)$ & 0.051 \\
\hline Others * & $4(10.5)$ & $2(6.9)$ & $2(22.2)$ & 0.233 \\
\hline Duration (days) & $73.85 \pm 67.86$ & $70.11 \pm 79.32$ & $82.25 \pm 32.41$ & 0.140 \\
\hline
\end{tabular}


Table 2. Cont.

\begin{tabular}{lcccc}
\hline & $\begin{array}{c}\text { All Patients } \\
(\boldsymbol{n}=\mathbf{3 8 )} \\
\text { No. (\%) }\end{array}$ & $\begin{array}{c}\text { IFSsOC } \\
(\boldsymbol{n}=\mathbf{2 9 )} \\
\text { No. (\%) }\end{array}$ & $\begin{array}{c}\text { IFSwOC } \\
(\boldsymbol{n}=\mathbf{9}) \\
\text { No. (\%) }\end{array}$ & $p$ Value \\
\hline $\begin{array}{l}\text { Antibiotic } \\
\quad \text { Duration (days) }\end{array}$ & $27.71 \pm 39.76$ & $22.95 \pm 43.83$ & $42.00 \pm 19.82$ & $\mathbf{0 . 0 0 5}$ \\
$\begin{array}{l}\text { Sequelae } \\
\text { Mortality }\end{array}$ & $2(5.3)$ & $0(0.0)$ & $2(22.2)$ & 0.051 \\
$\begin{array}{l}\text { Sequelae or } \\
\text { Mortality }\end{array}$ & $1(2.6)$ & $0(0.0)$ & $1(11.1)$ & 0.237 \\
\hline
\end{tabular}

Abbreviations: IFS, invasive fungal rhinosinusitis; SD, standard deviation. Bold indicates statistically significant $(p<0.05) .{ }^{*}$ Others included posaconazole and itraconazole.

\subsection{Clinical Signs Associated with IFSwOC}

Table 3 summarizes the clinical signs associated with IFSwOC. IFS patients have a statistically significantly higher risk for developing orbital complications if they had headache (OR 16.8, 95\% CI 2.66 to 106.14, $p=0.002)$ or fever $(p<0.001)$, sphenoid (OR $21.88,95 \%$ CI 3.295 to $145.28, p=0.001$ ), or posterior ethmoid sinus (OR 14.0, 95\% CI 1.23 to $158.84, p=0.035$ ) involvement, CRP level $\geq 1.025 \mathrm{mg} / \mathrm{dL}$ (OR 88.0, 95\% CI 4.76 to 1627.7, $p<0.001$ ) or ESR level $\geq 46.5 \mathrm{~mm} / \mathrm{h}$ (OR 15.0, 95\% CI 1.65 to 136.17, $p=0.019)$. Figure 3 demonstrated ROC analysis. The cutoff value of CRP was $1.025 \mathrm{mg} / \mathrm{dL}$ with a sensitivity of 0.875 , a specificity of 0.917 , and AUC of $0.958(p=0.001)$. The cutoff value of ESR was $46.5 \mathrm{~mm} / \mathrm{h}$ with a sensitivity of 0.750 , a specificity of 0.833 , and AUC of $0.839(p=0.012)$. Of the nine patients in IFSwOC group, three had poor prognosis, including one mortality and two with permanent neurologic sequelae (Supplementary Table S2). We compared these three patients with the other six patients in IFSwOC group who initially had orbital complications but fully recovered from the event. IFSwOC patients who were male, or who had posterior ethmoid sinus involvement, WBC count $\geq 9000 \mu \mathrm{L}, \mathrm{CRP}$ level $\geq 6.91 \mathrm{mg} / \mathrm{dL}$, or ESR level $\geq 69 \mathrm{~mm} / \mathrm{h}$, had a significantly poorer prognosis (Supplementary Table S3).

Table 3. The clinical signs associated with IFSwOC.

\begin{tabular}{|c|c|c|c|}
\hline & Odds Ratio & $95 \% \mathrm{CI}$ & $p$ Value \\
\hline \multicolumn{4}{|l|}{ Location } \\
\hline Maxillary & 0.060 & $0.009-0.376$ & 0.002 \\
\hline Sphenoid & 21.875 & $3.295-145.237$ & 0.001 \\
\hline Posterior ethmoid & 14.000 & $1.234-158.844$ & 0.035 \\
\hline \multicolumn{4}{|l|}{ Symptoms } \\
\hline Headache & 16.800 & 2.659-106.135 & 0.002 \\
\hline Fever & $8.25 *$ & & $<0.001$ \\
\hline \multicolumn{4}{|l|}{ Lab Data } \\
\hline $\begin{array}{l}\mathrm{CRP}(\geq 1.025 \\
\mathrm{mg} / \mathrm{dL})\end{array}$ & 88.000 & $4.758-1627.704$ & $<0.001$ \\
\hline $\mathrm{ESR}(\geq 46.5 \mathrm{~mm} / \mathrm{h})$ & 15.000 & $1.652-136.172$ & 0.019 \\
\hline
\end{tabular}

Abbreviations: IFS, invasive fungal rhinosinusitis; CI, confidence interval; CRP, C-reactive protein; ESR, erythrocyte sedimentation rate; RR, relative risk ratio. * There is no case having fever in IFSsOC, hence having infinite odds ratio. $\mathrm{RR}$ was shown instead of odds ratio here. 


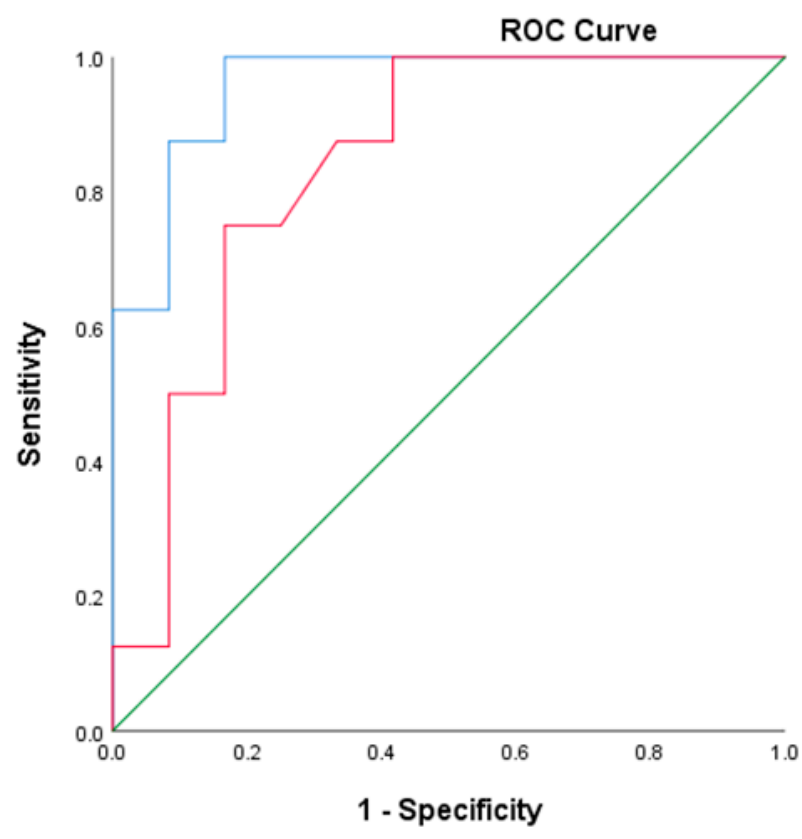

Source of the Curve

- CRP

- ESR

- Reference Line

Diagonal segments are produced by ties.

Figure 3. ROC graph for CRP and ESR. ROC curve of CRP and ESR as a risk factor of developing orbital complications in patients with IFS. The cutoff value of CRP was $1.025 \mathrm{mg} / \mathrm{dL}$ with a sensitivity of 0.875 , a specificity of 0.917 , and AUC of 0.958 ( $p=0.001$ ). The cutoff value of ESR was $46.5 \mathrm{~mm} / \mathrm{h}$ with a sensitivity of 0.750 , a specificity of 0.833 , and AUC of $0.839(p=0.012)$.

\section{Discussion}

Our study is the first one to identify the clinical signs associated with IFSwOC and its prognosticators. From our results, we found that IFS patients were at risk of developing orbital complications if they had the risk factors, including sphenoid and posterior ethmoid sinus involvement, headache and fever as presenting symptoms, and elevated CRP $(\geq 1.025 \mathrm{mg} / \mathrm{dL})$ and ESR $(\geq 46.5 \mathrm{~mm} / \mathrm{h})$ level.

In this study, the IFSwOC group more frequently had posterior ethmoid and sphenoid sinus involvement than the IFSsOC group. Furthermore, IFSwOC patients with posterior ethmoid sinus involvement had significantly worse survival outcomes. In IFS patients with neuro-orbital complications, it is believed that the fungal invasion usually originates from the paranasal sinuses and progresses through the mucosa and into the vasculature. After invading through the submucosal tissue, bone, and adjacent structures, fungi could directly invade the orbit, and then spread to the cavernous sinus and intracranial structures, causing serious complications [12]. The posterior ethmoid and sphenoid sinuses border the medial orbit, with only the thin lamina papyracea in between. There is minimal physical resistance for fungus to break through the thin bone and invade the orbit. On the other hand, the roof of the maxillary sinus (orbital floor) is much thicker than the lamina papyracea. This could explain why IFS in the maxillary sinus alone less commonly causes orbital symptoms. Similarly, the cavernous sinus and optic nerve are located at the posterolateral aspect of the sphenoid sinus, and they may be compromised in a similar manner. Direct fungal invasion into the cavernous sinus results in cavernous sinus thrombosis, which is a disastrous condition that would lead to orbital symptoms such as ptosis, chemosis, ophthalmoplegia, vision impairment, and blindness. Headache, fever, and sepsis could also develop, with the possibility of mortality. One of our patients suffered bilateral cavernous sinus thrombosis, and histopathology of the medial wall of cavernous sinus confirmed invasion by fungal hyphae.

In the present study, we attempted to identify risk factors of IFS leading to orbital complications. We found that the IFSwOC group had significantly more patients presenting 
with headache and fever, with a prevalence of $77.8 \%$ and $55.6 \%$, respectively, compared with the IFSsOC group. Turner et al. conducted a systematic review of 807 IFS patients, showing that $62.9 \%$ and $46.3 \%$ of patients had fever and headache, respectively, as presenting symptoms, but they did not compare the prevalence between subgroups [2]. In fact, to the best of our knowledge, the current study is the first study to compare factors between IFSwOC and IFSsOC groups. Our results may suggest that, if IFS patients presented with either fever or headache, clinicians should be aware of the possibility of developing orbital complications.

According to previous reports, elevated CRP level and severe neutropenia are significantly correlated with worse survival $[5,11]$. Gode et al. reported that CRP level $>4 \mathrm{mg} / \mathrm{dL}$ was associated with poor prognosis in AIFS patients [5]. Cho et al. also suggested that patients with a CRP level $>5.5 \mathrm{mg} / \mathrm{dL}$ had worse outcomes [11]. In this study, we found that elevated CRP $\geq 1.025 \mathrm{mg} / \mathrm{dL}$ significantly increased the risk of developing orbital complications in IFS patients, and a CRP level $\geq 6.91 \mathrm{mg} / \mathrm{dL}$ was significantly associated with poorer prognosis in IFSwOC patients. The cut-off values were calculated corresponding to the maximal value of Youden's index. Our findings were consistent with prior studies suggesting that elevated CRP level was a strong determinant of negative outcome. In addition, our series also discovered that WBC and ESR also were factors significantly related to IFSwOC. Specifically, ESR $\geq 46.6 \mathrm{~mm} / \mathrm{h}$ predicted orbital involvement in IFS patients. In the IFSwOC group, WBC $\geq 9000 / \mu \mathrm{L}$ and ESR $\geq 69 \mathrm{~mm} / \mathrm{h}$ both indicated poor prognosis. These results suggest that, if localized fungal rhinosinusitis progressed to systemic inflammation, the risks of permanent morbidities appeared to be higher.

In our series, nine of $38(23.7 \%)$ IFS patients presented with orbital symptoms. The prevalence of orbital disease in our study is lower than in prior studies. Turner et al. reported that orbital involvement was the most commonly seen complications of IFS, with a $49.6 \%$ prevalence rate in AIFS patients [2]. Chandrasekharan et al. found out that $73.5 \%$ of patients with IFS had orbital involvement, while only $12.1 \%$ of patients with non-invasive fungal rhinosinusitis had orbit compromise [18]. Trief et al. discovered that about $58.3 \%$ of patients with IFS had orbital disease, and those with orbital involvement, had higher mortality rates comparing with orbit sparing cases [19]. Our lower prevalence of orbital disease in our study may be due to the majority of our patients were CIFS, accounting for $84.2 \%$ of total patients, while AIFS was only $15.8 \%$. If we look at AIFS cases alone, six of six (100\%) patients had orbital involvement, while in CIFS patients only $9.4 \%$ had orbital disease. CIFS is known to have a more indolent disease course than AIFS, and it is possible that most of the CIFS patients had been diagnosed with the disease before orbital involvement occurred.

AIFS more commonly develops in immunocompromised patients, such as those with uncontrolled diabetes mellitus, severe neutropenia, or hematologic malignancies, those who are undergoing chemotherapy, or patients receiving bone marrow transplantation $[2,11,20]$. CIFS, on the contrary, occurs more frequently in immunocompetent hosts [21,22]. Our series revealed that, in 38 patients with IFS, none of them had hematologic disease, corticosteroid use, neutropenic status, or was receiving chemotherapy, and only $18.4 \%$ patients had diabetes mellitus. Even with subgroup analysis, only $33 \%$ of patients in the IFSwOC group had diabetes mellitus. In addition, there was no statistically significant difference between the IFSwOC and IFSsOC groups regarding their underlying medical comorbidities. Again, this may be accounted for the fact that the majority of cases had CIFS, which tend to consist of immunocompetent patients. However, the six patients with AIFS also had no underlying immunocompromised status. One possibility for this is small sample size. There are only few cases of IFS on immunocompetent hosts published in the previous literatures [23]. Though less prevalent, immunocompetent patients may develop AIFS as well, and they may also be at risk of suffering long-term complications, as two of our patients developed permanent neurologic sequelae and another one died of intracranial hemorrhage.

Fungal rhinosinusitis has been frequently found to be accompanied by bacteria coinfection. In our study, Aspergillus was the predominant identified fungal species, followed 
by Mucor, while Hemophilus influenza and Staphylococcus aureus were the most common isolated bacteria species. Superantigens and exotoxins of Staphylococcus aureus have been proved to participate in biofilm formation as well as impairment of local host immunity, which could contribute to the persistence and invasion of Staphylococcus aureus [24]. Similarly, various virulence factors of Hemophilus influenza involved in complement resistance, biofilm formation, and evasion of the host immune response promote the adhesion and internalization of Hemophilus influenza [25]. Therefore, mucosa barrier dysfunction and disrupted local immune system caused by certain bacterial infections, such as Staphylococcus aureus and Hemophilus influenza, may facilitate the invasion of fungus, contributing to the pathogenesis of IFS in both immunocompromised and immunocompetent patients. There are very few studies focusing on microbiota in fungal rhinosinusitis and fungal microbiota in chronic rhinosinusitis [26-28]. Our recent study using Next Generation Sequencing (NGS) technology uncovered the different bacterial and fungal microbiota between invasive and noninvasive fungal rhinosinusitis (unpublished data). We proposed that dysbiosis of sinus microbiota may play important role in the pathogenesis of IFS. Further investigation of fungal and bacterial microbiota interaction in IFS is needed in the future.

The mainstay of treatment for IFS is combining surgical debridement with systemic anti-fungal agents. Systemic anti-fungal therapies are an essential part of managing IFS. Amphotericin and the liposomal version are proved to have positive predictive value to survival [2,29]. Voriconazole is recommended for aspergillosis, and newer Azoles, such as isavuconazole and posaconazole, showing better bioavailability and less toxicity, are especially suitable for patients who have kidney disease or are intolerant to amphotericin B [29-32]. Combination therapy with two drugs (liposomal amphotericin B and isavuconazole or posaconazole) have been reported in cases with rhino-orbital-cerebral mucormycosis $[32,33]$. Surgical intervention significantly improves clinical outcomes and survival for patients with IFS $[2,9,34]$, and endoscopic surgery has been reported to yield successful and comparable treatment outcomes with open approaches $[2,35,36]$.

According to prior works, reported mortality rates for IFS ranged from $17.8 \%$ to $85.7 \%[5,11,12,17,35,37-40]$. In the present cohort, overall mortality rate was $2.6 \%$ in all patients, including $11.1 \%$ in the IFSwOC group and $16.7 \%$ among AIFS patients. Comparing only AIFS with cases from prior studies, the current study's mortality rate is lower, which could be credited to the following factors. First, all patients underwent surgical debridement, and all patients with orbital complications received systemic anti-fungal treatment. Even in the IFSsOC group, more than $65 \%$ of patients received postoperative systemic anti-fungal medications. This underscores the importance of aggressive debridement with antifungal therapy in managing this disease optimally. Second, there could be selection bias in our study population, as all of them enrolled in this study were patients deemed appropriate for surgical treatment. Those inoperable patients with clinically suspicious fungal rhinosinusitis were not included in the study owing to the lack of pathologic diagnosis. Consequently, the mortality rate could be underestimated, especially those who were inoperable often had poor general condition or high anesthetic risks.

Part of the key of successful surgical treatment is to debride as much diseased/necrotic sinonasal tissue as possible in order to lower the fungal load to a minimum. In clinical practice, however, it is not always possible to sample involved tissues for diagnosis, especially if the area of invasion is deep or high-risk (e.g., skull base, carotid artery). The lack of histopathologic proof does not rule out an invasive process. The European Organization for Research and Treatment of Cancer (EORTC) and the Mycoses Study Group (MSG) in 2019 has revised and updated their latest version of the Consensus Definitions of Invasive Fungal Disease in 2019 [41]. They classified invasive fungal disease into proven, probable, and possible categories. Proven invasive fungal disease is defined as evidence of fungal elements in the specimen. Diagnosis of probable or possible invasive fungal sinonasal diseases does not necessarily require a histopathologic proof of invasion of fungi into tissue, but it is proposed for immunocompromised patients. Nevertheless, this 
criteria does not fit into IFS well, as IFS can occur in immunocompetent patients. Liang et al. observed sinonasal fungal infection demonstrating transitional changes between each classification [42], which corresponds to Kosmidis's proposal that different forms of pulmonary aspergillosis should be viewed as a semicontinuous spectrum of disease and one form may evolve into another [43]. Therefore, we proposed that although there was no histopathologic evidence of invasive fungal disease, if the patient suffered a fungal rhinosinusitis with clinically apparent neuro-orbital complications, the patient still would benefit from aggressive treatment with early surgical debridement followed by systemic anti-fungal medications.

There are several limitations to the present study. This is a retrospective single institutional study in a tertiary referral center. Some data were missing or unclear in the medical records. The sample size is small, and it is even smaller with subgroup analysis, which decreases statistical power. As previously mentioned, there might be selection bias in our cohort, since inoperable patients were not included in the study. Further prospective studies with larger sample size are needed to establish the key risk factors and prognostic factors related to orbital complications in IFS patients.

\section{Conclusions}

To the best of our knowledge, this is the first study to identify the clinical signs associated with IFSwOC and prognosticators of the disease. Patients with invasive fungal rhinosinusitis who had sphenoid and posterior ethmoid sinus involvement, headache and fever as presenting symptoms, and elevated CRP $(\geq 1.025 \mathrm{mg} / \mathrm{dL})$ and ESR $(\geq 46.5 \mathrm{~mm} / \mathrm{h})$ level were at risk of developing orbital complications. Timely surgical debridement followed by systemic anti-fungal treatment could yield satisfactory treatment outcomes.

Supplementary Materials: The following are available online at https: / www.mdpi.com/article / 10.3390/jof7070573/s1, Table S1: Microbiology, Table S2: Clinical characteristics of 3 IFSwOC patients with poor prognosis, Table S3: Prognostic factors of IFSwOC.

Author Contributions: Conceptualization and methodology, M.-Y.L.; data collection, Y.-J.K., C.-Y.H., and W.-H.W.; analysis and interpretation of data, K.-H.T. and E.C.K.; writing-original draft preparation, K.-H.T.; writing—review and editing, M.-Y.L. and E.C.K.; funding acquisition, M.-Y.L. All authors have read and agreed to the published version of the manuscript.

Funding: This research was funded by the grant from the Taipei Veterans General Hospital (V109C-080, V110C-054) to MYL.

Institutional Review Board Statement: The study was conducted according to the guidelines of the Declaration of Helsinki, and approved by the Institutional Review Board of Taipei Veterans General Hospital (IRB NO: 2018-12-004CC, 13 December 2018).

Informed Consent Statement: Patient consent was waived due to the study is retrospective study.

Conflicts of Interest: All authors have no conflict of interest.

\section{References}

1. DeShazo, R.D.; O’Brien, M.; Chapin, K.; Soto-Aguilar, M.; Gardner, L.; Swain, R. A new classification and diagnostic criteria for invasive fungal sinusitis. Arch. Otolaryngol. Head Neck Surg. 1997, 123, 1181-1188. [CrossRef]

2. Turner, J.H.; Soudry, E.; Nayak, J.V.; Hwang, P.H. Survival outcomes in acute invasive fungal sinusitis: A systematic review and quantitative synthesis of published evidence. Laryngoscope 2013, 123, 1112-1118. [CrossRef] [PubMed]

3. Waitzman, A.A.; Birt, B.D. Fungal sinusitis. J. Otolaryngol. 1994, 23, 244-249.

4. Lueg, E.A.; Ballagh, R.H.; Forte, V. Analysis of the recent cluster of invasive fungal sinusitis at the Toronto Hospital for Sick Children. J. Otolaryngol. 1996, 25, 366-370. [PubMed]

5. Gode, S.; Turhal, G.; Ozturk, K.; Aysel, A.; Midilli, R.; Karci, B. Acute Invasive Fungal Rhinosinusitis: Survival Analysis and the Prognostic Indicators. Am. J. Rhinol. Allergy 2015, 29, e164-e169. [CrossRef] [PubMed]

6. Bhadada, S.; Bhansali, A.; Reddy, K.S.S.; Bhat, R.V.; Khandelwal, N.; Gupta, A.K. Rhino-orbital-cerebral mucormycosis in type 1 diabetes mellitus. Indian J. Pediatr. 2005, 72, 671-674. [CrossRef] [PubMed]

7. Dhiwakar, M.; Thakar, A.; Bahadur, S. Improving outcomes in rhinocerebral mucormycosis—Early diagnostic pointers and prognostic factors. J. Laryngol. Otol. 2003, 117, 861-865. [CrossRef] 
8. Monroe, M.M.; McLean, M.; Sautter, N.; Wax, M.K.; Andersen, P.E.; Smith, T.L.; Gross, N.D. Invasive Fungal Rhinosinusitis. Laryngoscope 2013, 123, 1583-1587. [CrossRef]

9. Sun, H.-Y.; Forrest, G.; Gupta, K.L.; Aguado, J.M.; Lortholary, O.; Julia, M.B.; Safdar, N.; Patel, R.; Kusne, S.; Singh, N. RhinoOrbital-Cerebral Zygomycosis in Solid Organ Transplant Recipients. Transplantation 2010, 90, 85-92. [CrossRef]

10. Hargrove, R.N.; Wesley, R.E.; Klippenstein, K.A.; Fleming, J.C.; Haik, B.G. Indications for Orbital Exenteration in Mucormycosis. Ophthalmic Plast. Reconstr. Surg. 2006, 22, 286-291. [CrossRef]

11. Cho, H.-J.; Jang, M.-S.; Hong, S.D.; Chung, S.-K.; Kim, H.Y.; Dhong, H.-J. Prognostic Factors for Survival in Patients with Acute Invasive Fungal Rhinosinusitis. Am. J. Rhinol. Allergy 2015, 29, 48-53. [CrossRef] [PubMed]

12. Thurtell, M.J.; Chiu, A.L.S.; Goold, L.A.; Akdal, G.; Crompton, J.L.; Ahmed, R.; Madge, S.N.; Selva, D.; Francis, I.; Ghabrial, R.; et al. Neuro-ophthalmology of invasive fungal sinusitis: 14 consecutive patients and a review of the literature. Clin. Exp. Ophthalmol. 2013, 41, 567-576. [CrossRef] [PubMed]

13. Hosseini, S.M.S.; Borghei, P. Rhinocerebral mucormycosis: Pathways of spread. Eur. Arch. Oto-Rhino-Laryngology 2005, 262, 932-938. [CrossRef]

14. Galetta, S.L.; Wulc, A.E.; Goldberg, H.I.; Nichols, C.W.; Glaser, J.S. Rhinocerebral mucormycosis: Management and survival after carotid occlusion. Ann. Neurol. 1990, 28, 103-107. [CrossRef] [PubMed]

15. Breadmore, R.; Desmond, P.; Opeskin, K. Intracranial aspergillosis producing cavernous sinus syndrome and rupture of internal carotid artery. Australas. Radiol. 1994, 38, 72-75. [CrossRef]

16. Hurst, R.W.; Judkins, A.; Bolger, W.; Chu, A.; Loevner, L.A. Mycotic Aneurysm and Cerebral Infarction Resulting from Fungal Sinusitis: Imaging and Pathologic Correlation. Am. J. Neuroradiol. 2001, 22, 858-863. [PubMed]

17. Parikh, S.L.; Venkatraman, G.; DelGaudio, J.M. Invasive Fungal Sinusitis: A 15-Year Review from a Single Institution. Am. J. Rhinol. 2004, 18, 75-81. [CrossRef]

18. Chandrasekharan, R.; Thomas, M.; Rupa, V. Comparative study of orbital involvement in invasive and non-invasive fungal sinusitis. J. Laryngol. Otol. 2011, 126, 152-158. [CrossRef]

19. Trief, D.; Gray, S.T.; Jakobiec, F.A.; Durand, M.L.; Fay, A.; Freitag, S.K.; Lee, N.; Lefebvre, D.; Holbrook, E.; Bleier, B.; et al. Invasive fungal disease of the sinus and orbit: A comparison between mucormycosis and Aspergillus. Br. J. Ophthalmol. 2015, 100, 184-188. [CrossRef]

20. Drakos, P.E.; Nagler, A.; Or, R.; Naparstek, E.; Kapelushnik, J.; Engelhard, D.; Rahav, G.; Ne'Emean, D.; Slavin, S. Invasive fungal sinusitis in patients undergoing bone marrow transplantation. Bone Marrow Transplant. 1993, 12, 203-208. [PubMed]

21. Deutsch, P.G.; Whittaker, J.; Prasad, S. Invasive and Non-Invasive Fungal Rhinosinusitis-A Review and Update of the Evidence. Medicina 2019, 55, 319. [CrossRef]

22. Stringer, S.P.; Ryan, M.W. Chronic invasive fungal rhinosinusitis. Otolaryngol. Clin. N. Am. 2000, 33, 375-387. [CrossRef]

23. Garcia-Giraldo, A.M.; Mora, B.L.; Loaiza-Castaño, J.M.; Cedano, J.A.; Rosso, F. Invasive fungal infection by Aspergillus flavus in immunocompetent hosts: A case series and literature review. Med. Mycol. Case Rep. 2019, 23, 12-15. [CrossRef]

24. Poddighe, D.; Vangelista, L. Staphylococcus aureus Infection and Persistence in Chronic Rhinosinusitis: Focus on Leukocidin ED. Toxins 2020, 12, 678. [CrossRef]

25. Duell, B.L.; Su, Y.-C.; Riesbeck, K. Host-pathogen interactions of nontypeableHaemophilus influenzae: From commensal to pathogen. FEBS Lett. 2016, 590, 3840-3853. [CrossRef]

26. Lu, Y.-T.; Wang, S.-H.; Liou, M.-L.; Shen, T.-A.; Lu, Y.-C.; Hsin, C.-H.; Yang, S.-F.; Chen, Y.-Y.; Chang, T.-H. Microbiota Dysbiosis in Fungal Rhinosinusitis. J. Clin. Med. 2019, 8, 1973. [CrossRef]

27. Zhao, Y.C.; Bassiouni, A.; Tanjararak, K.; Vreugde, S.; Psaltis, A.J.; Wormald, P.-J. Role of fungi in chronic rhinosinusitis through ITS sequencing. Laryngoscope 2018, 128, 16-22. [CrossRef]

28. Zhang, I.; Pletcher, S.; Goldberg, A.N.; Barker, B.; Cope, E.K. Fungal Microbiota in Chronic Airway Inflammatory Disease and Emerging Relationships with the Host Immune Response. Front. Microbiol. 2017, 8, 2477. [CrossRef]

29. Fokkens, W.J.; Lund, V.J.; Hopkins, C.; Hellings, P.W.; Kern, R.; Reitsma, S.; Toppila-Salmi, S.; Bernal-Sprekelsen, M.; Mullol, J.; Alobid, I.; et al. European position paper on rhinosinusitis and nasal polyps 2020. Rhinology 2020, 58, 1-464. [CrossRef] [PubMed]

30. Herbrecht, R.; Denning, D.; Patterson, T.F.; Bennett, J.E.; Greene, R.E.; Oestmann, J.-W.; Kern, W.V.; Marr, K.A.; Ribaud, P.; Lortholary, O.; et al. Voriconazole versus Amphotericin B for Primary Therapy of Invasive Aspergillosis. N. Engl. J. Med. 2002, 347, 408-415. [CrossRef] [PubMed]

31. Maertens, J.A.; Raad, I.I.; Marr, K.A.; Patterson, T.; Kontoyiannis, D.P.; Cornely, O.; Bow, E.J.; Rahav, G.; Neofytos, D.; Aoun, M.; et al. Isavuconazole versus voriconazole for primary treatment of invasive mould disease caused by Aspergillus and other filamentous fungi (SECURE): A phase 3, randomised-controlled, non-inferiority trial. Lancet 2016, 387, 760-769. [CrossRef]

32. Fadda, G.L.; Martino, F.; Andreani, G.; Succo, G.; Catalani, M.; Di Girolamo, S.; Cavallo, G. Definition and management of invasive fungal rhinosinusitis: A single-centre retrospective study. Acta Otorhinolaryngol. Ital. 2021, 41, 43-50. [CrossRef]

33. Andreani, G.; Fadda, G.; Gned, D.; Dragani, M.; Cavallo, G.; Monticone, V.; Morotti, A.; De Gobbi, M.; Guerrasio, A.; D'Avolio, A.; et al. Rhino-Orbital-Cerebral Mucormycosis after Allogeneic Hematopoietic Stem Cell Transplantation and Isavuconazole Therapeutic Drug Monitoring during Intestinal Graft versus Host Disease. Mediterr. J. Hematol. Infect. Dis. 2019, 11, e2019061. [CrossRef] 
34. Khor, B.-S.; Lee, M.-H.; Leu, H.-S.; Liu, J.-W. Rhinocerebral mucormycosis in Taiwan. J. Microbiol. Immunol. Infect. 2003, 36, 266-269. [PubMed]

35. Chen, C.-Y.; Sheng, W.-H.; Cheng, A.; Chen, Y.-C.; Tsay, W.; Tang, J.-L.; Huang, S.-Y.; Chang, S.-C.; Tien, H.-F. Invasive fungal sinusitis in patients with hematological malignancy: 15 years experience in a single university hospital in Taiwan. BMC Infect. Dis. 2011, 11, 250. [CrossRef] [PubMed]

36. Kasapoglu, F.; Coskun, H.; Ozmen, O.A.; Akalin, H.; Ener, B. Acute invasive fungal rhinosinusitis: Evaluation of 26 patients treated with endonasal or open surgical procedures. Otolaryngol. Neck Surg. 2010, 143, 614-620. [CrossRef] [PubMed]

37. Payne, S.J.; Mitzner, R.; Kunchala, S.; Roland, L.; McGinn, J. Acute Invasive Fungal Rhinosinusitis. Otolaryngol. Neck Surg. 2016, 154, 759-764. [CrossRef]

38. Roxbury, C.R.; Smith, D.F.; Higgins, T.S.; Lee, S.E.; Gallia, G.L.; Ishii, M.; Lane, A.P.; Reh, D.D. Complete Surgical Resection and Short-Term Survival in Acute Invasive Fungal Rhinosinusitis. Am. J. Rhinol. Allergy 2017, 31, 109-116. [CrossRef] [PubMed]

39. Wandell, G.; Miller, C.; Rathor, A.; Wai, T.H.; Guyer, R.A.; Schmidt, R.A.; Turner, J.; Hwang, P.H.; Davis, G.E.; Humphreys, I.M. A multi-institutional review of outcomes in biopsy-proven acute invasive fungal sinusitis. Int. Forum Allergy Rhinol. 2018, 8 , 1459-1468. [CrossRef]

40. Hirabayashi, K.E.; Idowu, O.; Kalin-Hajdu, E.; Oldenburg, C.E.; Brodie, F.L.; Kersten, R.C.; Vagefi, M.R. Invasive Fungal Sinusitis: Risk Factors for Visual Acuity Outcomes and Mortality. Ophthalmic Plast. Reconstr. Surg. 2019, 35, 535-542. [CrossRef]

41. Donnelly, J.P.; Chen, S.C.; Kauffman, C.A.; Steinbach, W.J.; Baddley, J.W.; Verweij, P.E.; Clancy, C.J.; Wingard, J.R.; Lockhart, S.R.; Groll, A.H.; et al. Revision and Update of the Consensus Definitions of Invasive Fungal Disease From the European Organization for Research and Treatment of Cancer and the Mycoses Study Group Education and Research Consortium. Clin. Infect. Dis. 2019, 71, 1367-1376. [CrossRef] [PubMed]

42. Hua, M.-W.; Wu, C.-Y.; Jiang, R.-S.; Chang, C.-Y.; Liang, K.-L. Validate the classification of fungal rhinosinusitis: A retrospective analysis of 162 patients at a single institution. Clin. Otolaryngol. 2019, 44, 1131-1137. [CrossRef] [PubMed]

43. Kosmidis, C.; Denning, D. The clinical spectrum of pulmonary aspergillosis. Thorax 2014, 70, 270-277. [CrossRef] 